\title{
Understanding social enterprise country models: Spain
}

Ramon Fisac-Garcia and Ana Moreno-Romero

Research Group on Sustainable Organizations, Universidad Politécnica de Madrid, Madrid, Spain

\begin{abstract}
Purpose - The purpose of this paper is to describe the historical institucional context of Spain in the past 40 years and toanalyze the infiuenceof institutional factors in the current model of social enterprise existing in the country.

Design/methodology/approach - This study draws on the theory of historical institutionalism, national-level empirical data and Kerlin conceptual framework (2013) that informs modeis of social enterprise.

Findings-This paper describe sorne traits of Spain's social enterprise that can be explained by the evolution of its institucional context in the past 40 years. It helps to validate, from a historical institutionalistic perspective, aspects of theKerlin frameworkfor social enterprise models.It also begins to show that the analysis of regional differences in the conte.xtshould be taken into consideration when examining a country's social enterprisespace.

Research limitations/implicatious - This discussion paper encourages academics to analyze regional differences in the emergence of social enterprise within a country. The main limitation of the paper is the lack of an "official" definition of social enterprise in Spain.

Origiuality/value - This paper appliesa valuable framework toa country witha uniquepolitical and economic history in the past 40 years. It contributes to enrich the research on the emergence and development of social enterprises in a variety of contexts and advances understanding of how regional differences inside a country influence the development of social enterprises.
\end{abstract}

Keywords lnstitutions, Spain, Social enterprise, Historical institutionalism

\section{Introduction}

Social enterprise is a concept which has different definitions across countries and regions (Defoumy and Nyssens, 2006; Kerlin, 2009). The boundaries of the concept are still blurred (Galera and Borzaga, 2009; Doherty et al., 2014), but its core principies are well-defined:the adoption of sorne form of commercial activity to generate revenue, and the pursuit of social goals (Laville and Nyssens, 2001 Mair and Martí, 2006; Peredo and McLean, 2006; Peattie and Morley, 2008; Doherty et al, 2014).

The lack of consensus on the concept delimitation could inhibit the development of a consistent body of research (Young and Lecy, 2013). To better understand the typology and the factors that explain the emergence of social enterprise, work has been done in recent years drawing from different theories and perspectives (Haugh, 2012). Particular!y, given thatsocial enterpriselies within boundaries of the private, publicand nonprofit sectors (Defourny and Nyssens, 2010; Doherty et al, 2014), the analysis of 
social enterprise from an institutional theory framework (DiMaggio, 1988) can help to better understand the relationship of these organizational forms within a socioeconomic context and within the institutions they interact with (Kerlin, 2010).

Country-level institutional factors explain, in part, the emergence and typology of social enterprise (Borzaga and Defourny, 2001; Austin et al., 2006; Defourny and Nyssens, 2010; Kerlin, 2010) because such enterprises face pressure from diverse (Cooney, 2006) and sometimes conflicting (Pache and Santos, 2012) institutional demands. Such explanations gain importance in light of the fact that different forms of social enterprise are not strictly regionally separated (Young and Lecy, 2013), but can reveal a diversity of approaches in neighboring countries or even inside the same country (Sepulveda, 2009; Evers et al., 2014).

Kerlin (2013) in a recent work draws on historical institutionalism to examine how institutional contexts influence the development of social enterprises across different countries. She constructs a conceptual framework that helps to explain how institutional processes shape social enterprise in different contexts and help develop a typology of social enterprises.

Responding to the need to compare social enterprise across dimensions of place and form (Austin et al., 2006; Doherty et al., 2014), the general objective of this article is to apply the Kerlin (2013) framework in the case of Spain in two different dimensions:

(1) At the national level, analyzing the historical institutional context of Spain in the past 40 years with the aim of suggesting a national model for social enterprise.

(2) At the regional level, exploring if the diverse contexts that exist in the 17 Autonomous Communities that form Spain can yield to differences in the formation of social enterprises.

The next section describes an overview of social enterprise in Spain, explaining the general approach to the concept existent in the country, reviewing its history and painting a picture of the field. Then, we apply Kerlin's (2013) institutional framework to the case of Spain, analyzing the five major elements that influence the conformation of country-level social enterprise models: the culture, political context, economic situation, civil society and international influences. In the last section, we will discuss the model of social enterprise which best fits the Spanish case and we will arrive at the main conclusions of the research.

\section{Overview of the social enterprise in Spain}

\subsection{Social enterprise concept in Spain}

Spain is not an exception in having a terminological conflict delimiting social enterprise. Along with the ambiguity on what exactly this organizational model is - a general challenge all over the world - there is also debate in Spain around terms which refer to similar or overlapping concepts (Galera and Borzaga, 2009), mainly the terms "social economy" and "third sector".

Several concepts have been used to define a set of organizations and initiatives that are neither public nor for-profit and private that go beyond private individual interests. Depending on the specific country, this sector goes by different names, but there is consensus on calling it the third sector (Nogales, 2011). In Spain, the third sector is composed of those private organizations that "emerged from citizen or social initiative under different forms that are guided by solidarity, common good 
and non-profit principles that enhance the recognition and practice of social rights" (BOE, 2006, Article 2.8).

According to Defourny and Nyssens (2006), two theoretical approaches to the third sector have gradually spread internationally: the social economy and the nonprofit school approaches, the main difference is their aim to benefit either their members or a larger collective.

Following Spain's collective recent history and the European influence, social economy is the main approach of the third sector in the country. In the past 40 years, much effort has been made to promote this concept and to define the legal forms included in it: cooperatives, labor (worker-owned) societies, mutual benefit societies and others (CEPES, 2014a).

Social enterprises are widely considered to comprise a broad "spectrum" of types (Dees, 1996), intersecting with for-profit and nonprofit (and occasionally public) sectors (Emerson and Twersky, 1996; Dart, 2004). In Europe (and consequently in Spain), the concept has much clearer boundaries (Spear, 2010) and focuses especially on participation, governance and incentive structure (Pestoff, 2009).

The relation of social enterprise to the social economy is essential in Spain (Díaz et al., 2012) and, therefore, a definition of social enterprise that is more representative would be that proposed by the EMES European Research Network (Borzaga and Defourny, 2001; Defourny and Nyssens, 2012). According to this organization, social enterprise is shaped by three sets of criteria which closely relate to social economy and the third sector (Nogales, 2011) and which help organizations to "position themselves within the galaxy of social enterprises" (Defourny and Nyssens, 2012, p. 12)[1].

In a general overview, social enterprise in Spain can be characterized by a group of relatively small and local organizations carrying out economic activities, mainly oriented to employment provision, that present a wide range of legal forms and share some values with the third sector and social economy.

\subsection{The complexity of mapping Spanish social enterprise}

Given that the most extended concept of social enterprise in Spain is the ideal-type described by EMES (Defourny and Nyssens, 2012), the related legislation affecting social enterprises does not define a unique legal form to embody this model of organization[2]. Therefore, social enterprise mapping in Spain is extremely complex and has not yet been done[3].

Given these limitations, it is only possible to measure the size of social economy because its legal forms are defined. Social economy is significant for the Spanish economy, representing more than 150 million euros and over 12 per cent of the gross domestic product (GDP) (CEPES, 2014a). According to CEPES (2014a, 2014b), in 2013, there were 2,215,000 people employed by 44,563 organizations in the social economy, which accounts for 12 per cent of Spain's GDP (150,000 million euros), mainly: 24,597 co-operatives, 11,322 worker-owned labor societies (sociedades laborales), 450 social employment centers (centros especiales de empleo de economía social), 391 mutual benefit societies, 198 fishermen guilds, 205 work integration social enterprises (empresas de inserción), 7,212 associations, 64 foundations and 124 traditional enterprises. Within this pool of organizations, some may not qualify as social enterprises[4], while some of them lie closer to the ideal type of social enterprises. 
Acknowledging these limitations, we can offer a preliminary functional "working description" which indentifies some traits of social enterprises in Spain:

- Their activities are essentially linked to social integration employment and the provision of social services and community care (Monzón and Chaves, 2012). These fields are related to the welfare provision that Government contracts out to social-driven organizations. A high propensity exists to create labor-intense jobs at the local level (Chaves, 2008) that do not demand a big capital investment. There is a high degree of specialization in specific sectors: 55.8 per cent of employment is generated in the service sector -principally trade, hotels and restaurants, education and social work, followed by 24 per cent in industry, 12.4 per cent in construction and 7.8 per cent in agriculture (Barrera, 2008).

- The size of these organizations is small, they act locally and they are embedded in local contexts. The small size generates little visibility, so they are normally organized in networks (both in the regional and national level) to enhance their visibility and to dialogue with public bodies and institutions. Cross-sector associations represent different types of entities from different sectors (Valdés Dal-Re, 2009). That means that the main actor within this institutional life is not social economy organizations themselves, but second-tier organizations or federations that represent social economy organizations. Today, the Spanish social enterprise model is characterized by networked federations and the presence of supporting institutions (Barrera, 2008).

- The concern about local community life sparks the creation of new social enterprises. The emergence is usually motivated by the knowledge of local social problems and the promoters' capability to detect new needs (Salinas and Rubio, 2001). The highly degree of embeddedness in the territory and the local context generates a close contact with beneficiaries.

- Democratic principles and citizen participation mechanisms are characteristic of most Spanish social enterprises. This influence comes from the European social economy tradition. Social enterprises do not only make a contribution to the market economy but they also help to improve and sustain forms of active citizenship (Hulgård, 2010).

- Social enterprises show a high degree of autonomy. Most social enterprises work in collaboration with public bodies and institutions, but remain independent in terms of objectives, management and governance.

- Social enterprises in Spain take multiple legal forms from different overlapping pools (the third sector, the social economy and private sector), but the main legal forms correspond to those of the social economy, mainly: nonprofit co-operatives (cooperativas de iniciativa social), mutuals, labor worker-owned societies (sociedades laborales), social employment centers (centros especiales de empleo de economía social), mutual benefit societies and work integration social enterprises (empresas de inserción). Some businesses, foundations and associations also form part of the social enterprise legal landscape.

- Most of the social enterprises rely on commercial revenue but they are complemented with subsidies and fiscal advantages to different degrees. Different mechanisms exist today to support social economy entities such as 
various tax treatments, aid to the direct creation of jobs (which are encouraged by subsidies for salaries or reductions in contributions for social security of workers) or a national fund granting a small percentage of income tax to social service activities (Chaves, 2008). The State supports, while their competitiveness is encouraged.

\subsection{Historical development of the field}

Though there had been some older collective experiences in the Middle Ages[5], Spain's first examples of associations date back to the mid-nineteenth century. The Weavers' Association (Asociación de Tejedores) of Barcelona, the first trade union in Spain, was founded in 1840 (Monzón and Chaves, 2012). In 1842, the Weavers' Industrial Company (Compañia Fabril de Tejedores) was created, and it is considered to be the first production cooperative in Spain (Reventós, 1960). In the first half of the twentieth century, social enterprises in Spain were characterized by small organizations promoted by citizens at a local level, with a lack of institutions at the national level.

Since the encyclical letter Rerum Novarum by Pope Leo XIII in 1891, the Catholic Church has had a big influence in Europe promoting people's wider social responsibilities (Spear, 2010) and has been key to the development of the cooperative movements. In Spain, the best example would be the Mondragón cooperative group by father José María Arizmendiarrieta. In 2010, Modragón was the seventh largest corporation in Spain and was described as "one of the wonders of the social enterprise world" (Spear, 2010, p. 45). Therefore, the Catholic Church had a preeminent role in the provision of social services (Ruiz-Olabuénaga et al., 1999) and in addressing exclusion issues during that time.

Since the civil war that took place between 1939 and 1945, Francisco Franco (1939-1975) ruled the country for more than 35 years as a dictatorship. During this period, the formation of associations was restricted - especially those based on specific ideologies - so organization creation were discouraged during those days, even if they had assistance goals.

The emergence of modern social enterprise movements in Spain can be traced to the decade of late 1970s and 1980s (Salinas and Rubio, 2001), a period of important political and social transformations in the country that has been named the Transition period (la Transición), that correspond to the shift from Franco's dictatorship to democracy.

During the 1970s and 1980s, different social-oriented initiatives emerged to promote employment in workers' cooperatives and labor companies as a result of the employment crisis in Europe (Barrera, 2008; Monzón and Chaves, 2012). In the coming years, some normative developments followed, and even if the economic context improved after that decade, more public programs were set up to encourage employment in cooperatives and labor companies.

In the 1990s, two trends emerged that are influencing today's landscape of social enterprise in the country: the beginning of the legislative decentralization on social issues and the creation of local networks of social-oriented organizations. In 1992 the 17 Autonomous Communities that form Spain acquired the capacity to legislate cooperatives within their own territory (Barrera, 2008), so the central Government stopped being the unique legislator. Also, regional federations - particularly those of the cooperatives and labor companies - were created in most of the regions. They became 
rapidly professionalized, not only in representing their own sectors but also in managing public regional, national and European sectors (Barrera, 2008). Balancing the atomization of networks, the institutionalization of the social economy also took place at a national level with the creation of different national bodies to improve coordination, visibility and representation within this sector[6] (Barrera, 2008).

From the 1990s onward, the social economy in Spain grew, broadening the type of organizations that were part of this movement and establishing different strategic actions (Barrera, 2008), like congresses, the creation of a small and medium enterprises (SME) observatory, the benchmark for good practices in the international sphere (Europe and Latin America), and the promotion of employment in the social economy through different measures, mainly subsidies.

The last milestone of the recent history of social enterprise was achieved with Spain becoming the first European country to pass a Social Economy Act (Monzón and Chaves, 2012). This Law is not intended to regulate the sector because each type of agent has its own normative texts (cooperatives, mutual societies, etc.) (Fajardo, 2009), but to define the concept of social economy, identify the entities that compose it and describe some measures to promote and develop the field.

\section{Application of Kerlin's model to the Spanish case}

Variations in social enterprise around the world are in part due to their connection with specific socioeconomic conditions within their context (Kerlin, 2009). In her recent work, Kerlin (2013) constructs a preliminary framework for large institutional processes shaping social enterprise and proposes a preliminary typology of models in different countries. The study proposes five major macro-institutional processes for models of social enterprise (Kerlin, 2013) (Figure 1):

(1) A rich mix of cultural, local, regional and global hierarchies (including social classes) and political - economic histories.
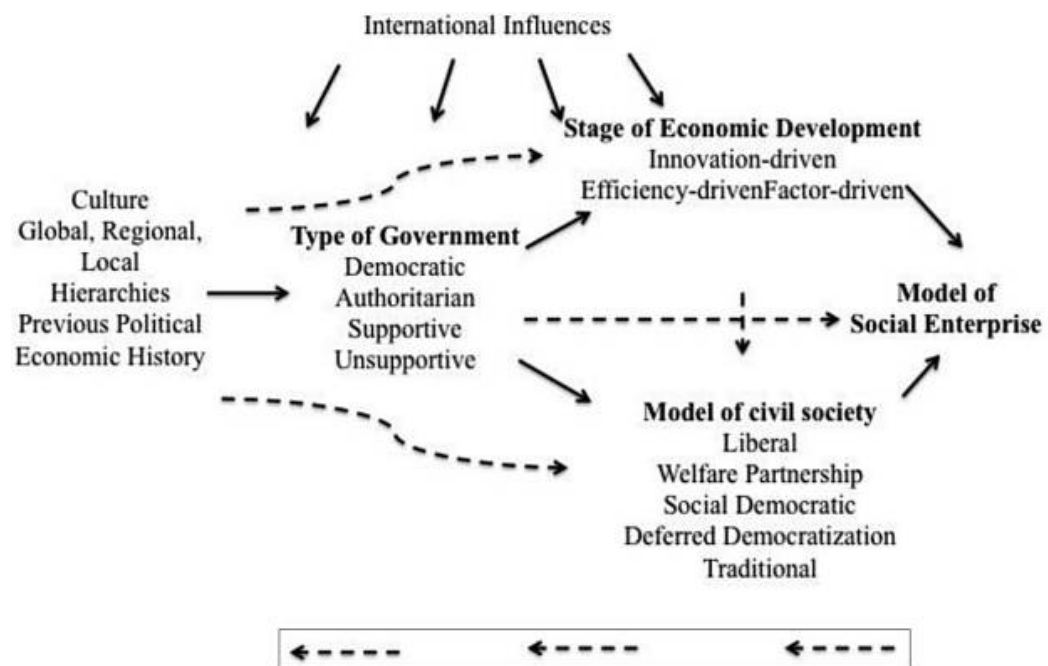

Source: Kerlin (2013) 
(2) The type of government.

(3) The stage of economic development.

(4) The model of civil society.

(5) The international influences.

Typologies for economic development and civil society are combined in Kerlin's framework to explain different models of social enterprise. According to her classification, we can identify five social enterprise models according to the type of civil society and the type of economy in a country: sustainable subsistence, autonomous mutualism, enmeshed focused, dependent focused and autonomous diverse.

In the following sections, we will describe the five macro-institutional processes for Spain, highlighting the aspects that can have an influence in the current landscape of social enterprise in Spain.

\subsection{Analysis of Spain's context, culture and society}

Spain is a democratic parliamentary monarchy composed by 17 Autonomous Communities or regions. It is a member of the European Union and is its second largest country by surface and the fifth by population, with an estimated 46.2 million residents (INE, 2013).

Two important historical events have had a major importance in the country's recent past:

(1) the pacific transition from Franco's dictatorship to a democratic parliamentary monarchy (second half of the 1970s); and

(2) the admission of Spain as a member of the European Union in 1986.

The ethnic composition of the native citizens can be considered as homogenous, even if, in the past 20 years, important immigration movements have occurred. The last census estimates the foreign population at 5.3 million -11.2 per cent of the total population, the two main communities being those of Romania $(798,104)$ and Morocco $(773,966$; INE, 2013).

In contrast, the cultural composition of Spain is heterogeneous, with many different cultural groups resulting from different regions. Those cultures are strongly associated with the main languages that co-officially exist with the Spanish language in the country: Catalan, Basque and Galician[7].

The social class composition in Spain is characterized by the importance of two large groups:

(1) the old and new middle class that contain 49 per cent of the employed population; and

(2) the working class - accounting for 24 per cent of the working population - that is mainly composed by nonqualified workers (Fundación Encuentro, 2011).

The middle class has been growing since the Franco's regime period due to the transformation of the economy - from agriculture-based to a service-based economy, easier access to education, the specialization of the labor force and other factors (Fundación Encuentro, 2013). 
Spain's main religion is Catholic Christian. Since this religion is based on values of fraternity, charity and assistance to others, according to Spear (2010), we could argue that this institution has played an important role in shaping the activities of social enterprise in Spain, especially empowering actors with resources and legitimatizing the initiative.

To analyze some attitudes and cultural values in Spain, we will use Hofstede's cultural dimensions (Hofstede, 2014). The six cultural dimensions gathered by Hofstede by the time of writing this paper are: power distance, individualism, masculinity, uncertainty avoidance, pragmatism and indulgence (Hofstede et al., 2010). We argue that the dimensions of cultural values that are related to the emergence of social enterprise in Spain are individualism and uncertainty avoidance:

- The individualism (IDV) dimension scores 51/100. Therefore, Spain, in comparison with the rest of the European countries (except for Portugal), is considered a collectivist country (Hofstede, 2014). Tiessen (1997) identifies how collectivism and individualism each support different key functions of entrepreneurialism. As individualism specifically supports the creation of variety through innovation, collectivism supports the leveraging of resources internally and through external ties. These facts lead us to believe that Spanish society values community and, therefore, responsiveness to community problems would be expected.

- Uncertainty avoidance (UAI) is high with 86 points of 100 , a score that according to Hofstede constitutes one of the most outstanding characteristics of Spanish people. Attitude toward uncertainty is key to determine the probability to start a venture like a social enterprise and to understand the conditions necessary for this to happen. In this sense, we suggest that the Spanish are not especially inclined towards entrepreneurship and they value environments that limit risk-taking. This could support the fact that Spain has developed a good body of normative frameworks around social economy that fight uncertainty and promote stability. The limited inclination towards entrepreneurship is confirmed by the Global Entrepreneurship Monitor 2013, that considers Spain an innovation-driven country where entrepreneurial capability perception is low even if the presence of opportunity is consistently high (Amorós and Bosma, 2013). Nevertheless, uncertainty avoidance does not imply a smaller size of Spanish social economy (which is similar to other European countries with higher tendency to entrepreneurship) (Fajardo, 2009), but we argue that it has an effect on the creation of a protective environment for all forms of entrepreneurship (support of the State, normative framework, etc.).

\subsection{Analysis of Spain's government and political context}

Social enterprises are embedded in the political context (Defourny and Nyssens, 2006) and in the past 40 years, the construction of the social enterprise concept in Spain has been influenced by different political factors.

Political context during Franco's dictatorship was characterized by the suppression of civil liberties and the reduction of the social and political space, so in the late 1960s to early 1980s, few civil society organizations existed. They were characterized by a strong ideology, simple organizational structures, generalist objectives and the desire to be distant to bureaucracy and traditional for-profit enterprises (Salinas and Rubio, 2001). 
During the Transition period, in the late 1970s and 1980s, the context changed, democratic principles were instilled and all political forces were eager to forget the recent authoritarian past. Participation and consensus were main drivers in all political actions. Political parties were ready to listen and to involve all the stakeholders within the political process to establish democracy (Valdés Dal-Re, 2009). The result was the construction of solid and legitimate institutions, including those related to social enterprise. Expressions of participative citizenship were progressively encouraged in the achievement of social harmony, good citizenship and economic development (García Delgado, 2003). This fact boosted the role of society in the construction of welfare. This fact also reflects the two major trends on global policy-making in Europe since the mid-1980s described by Hulgård (2010):

(1) the privatization of the public responsibility for public welfare; and

(2) experimentation with new forms of solidarity and collectivity by civil society.

The integration in the European Union took place in 1986 was also important for the political context of Spain. European influence is notorious in different dimensions: economic, social, cultural and others. Even if legal autonomy of each country within the Union exists, the Members are committed by the European guidelines and directives to translate some common European features to their legal frameworks.

In a rather short period, Spain built a welfare state, where the State plays a key role in the protection and promotion of the economic and social wellbeing of its citizens. The welfare state model has a direct relation with the development of the social enterprise. As Chaves (2008) points out, the welfare system model takes the responsibility of offering most of the social or general-interest services to its citizens, directly, through the public sector or by leaning on the social economy.

Today, the Spanish political scene is influenced by the division of the country into 17 Autonomous Communities or regions that have their own government and parliament. It can be considered a federal state with a complex equilibrium of competencies between central and regional powers. During the past decades, Autonomous Communities have been acquiring competences in most of the social policy fields that affect social enterprise (education, health care, social care and active labor market policies) and most of them now have normative powers to pass legislation according to the specific needs of the regions.

The positive side of this configuration is that regional politicians are more capable of responding to specific challenges of their own territory (Barrera, 2008) and to craft better solutions to social exclusion and welfare, most of them of a specifically local nature (Brandsen et al., 2012). Additionally, communities and social agents are capable of channeling their concerns and demands to the regional level more effectively.

The negative side of this region-based system is the legislative and institutional inflation that Spain suffers from in this area, with various laws (Monzón and Chaves, 2012) and the duplication of entities (Fajardo, 2009), considering those at the regional and national level.

\subsection{Analysis of Spain's economy}

During the years following 1978, Spain suffered a radical transformation around the modernization of the economy, the reception of the European influence, the 
modernization of the productive structures and the improvement of the restrictions attached to the previous regime (García Delgado, 2003).

In those Transition years, the picture of the national economy changed toward an industrialized modern economy. The agriculture-based economy (25 per cent of total working force back in 1975 worked in the agriculture) transitioned into a service-based economy, the industrial network expanded and people migrated from rural to urban areas (García Delgado, 2003). Being an economy, traditionally dependent on agriculture, the business aptitude emerged throughout the country. We argue that in those early years, Spanish economy could be described as efficiency-driven where productive efficiency is expanded and product quality improved, both facilitated by improving state policies.

The impact of European policies was notorious (Monzón and Chaves, 2012) in these modernizing efforts, and lots of economic resources and political support were offered from the European Union: European Social Fund, the European Regional Development Fund, the LEADER initiative, European directives and legislation, etc. Today, Spain has an innovation-driven economy according to the last Global Competitiveness Report (Schwab, 2013) of the World Economic Forum, where it ranks as the 35th most competitive economy in the world.

Spain's GDP reached in 20121.352 US\$ billion, which means a GDP per capita of US\$ 29,289 (Schwab, 2013). An analysis of GDP shows that today Spain is a highly sector-oriented economy, as the service sector accounts for 71 per cent of sectorial value-added as a share of GDP (Schwab, 2013).

The economic crisis had a big impact in the country, intensifying some existing structural deficiencies in the goods, labor and financial markets. Difficult flow of bank loans and a decrease in general consumption have caused an increase in business failures (Amorós and Bosma, 2013). Consequently, unemployment is one of the most important concerns of Spaniards, with an unemployment rate reaching 25 per cent of the working population (INE, 2013). Moreover, another common trait is the rise of temporary contracts, with as much as one third of people, until recently, in temporary employment in Spain (Brandsen et al., 2012).

One of the main outcomes of the crisis has been the realization that there are severe differences among regions in Spain. Some figures can help us understand the differences among regions:

- Unemployment rate presents strong differences between regions. In Andalusia, unemployment reached 34.6 per cent on average, followed by Extremadura and the Canary Islands (both 33.0 per cent). In contrast, the Basque Country (14.9 per cent), Navarra (16.2 per cent) and Cantabria (17.7 per cent) present the lowest rates (INE, 2013).

- The regional GDP per capita and the Regional Competitiveness Index (RCI), a measure of competitiveness at the regional level developed by the European Commission, presenting high variability among different regions in Spain. Table I contains the scores for the 2013 RCI analysis (Annoni and Dijkstra, 2013) and the regional GDP data (INE, 2014). Spain is one of the countries in the European Union where differences in RCI scores are more significant among regions, scores varying from 0.5 points (Comunidad de Madrid) to -1.098 points (Ciudad Autónoma de Ceuta). The GDP per capita varies from €29,959 (País Vasco) to $€ 15,026$ (Extremadura). 


\begin{tabular}{lcc}
\hline Region & RCI 2013 score & GDP per capita 2013 \\
\hline Galicia & $-0,458$ & 20,399 \\
Principado de Asturias & -0.340 & 20,591 \\
Cantabria & -0.277 & 21,550 \\
País Vasco & 0.175 & 29,959 \\
Com. Foral de Navarra & -0.025 & 28,358 \\
La Rioja & -0.347 & 25,277 \\
Aragón & -0.351 & 24,732 \\
Comunidad de Madrid & 0.479 & 28,915 \\
Catilla y León & -0.460 & 21,879 \\
Castilla La Mancha & -0.690 & 17,780 \\
Extremadura & -0.813 & 15,026 \\
Cataluña & -0.109 & 26,666 \\
Comunidad Valenciana & -0.349 & 19,502 \\
Illes Balears & -0.521 & 23,446 \\
Andalucia & -0.649 & 16,666 \\
Región de Murcia & -0.457 & 17,901 \\
Ciudad Autónoma de Ceuta & -1.098 & 18,771 \\
Ciudad Autónoma de Melilla & -0.930 & 16,426 \\
Canarias & -0.618 & 18,873
\end{tabular}

Source: Annoni and Dijkstra (2013)

\subsection{Analysis of Spain's civil society}

The proactivity of civil society is a key factor to understanding the emergence of social enterprise. Its social mission is an expression of the concerns of citizens about community and an attempt at the betterment of society. In some cases, social entrepreneurship is even considered as a response of civil society to answer the problems that the Welfare system has not been able to address (Leadbeater, 1997) and as a manifestation of the power of civil society (Hulgård, 2010).

In Spain, the emergence of civil society organizations and the nonprofit sector (including some social enterprises) took place in the past 40 years and can be explained by the following three main factors (Salinas and Rubio, 2001):

(1) The late and slow development of the welfare state and the need of social policies when it was not already fully operative.

(2) The progressive contracting out of social services from the Public Administration (Rodríguez and Monserrat, 1997).

(3) The development of values such as solidarity, volunteerism and participation among Spanish society.

The transition to democracy brought a boom in associational life, as political space for nonprofit activities was freed up and claimed by emerging social movements and citizen action. Montagut (2000) identified changes in popular mindsets in Spanish society during that period, when people assumed a collective responsibility that was previously delegated to Government.

From the 1980s, Public Administration started contracting out the provision of social services. In this period, new demands emerged mainly derived from typical exclusion 
processes of postindustrial societies (immigration and long-term unemployment) and a new demographic reality. As Administrations had limited capacity to answer all these needs, external forms of producing and delivering social services emerged. The public subsidies to nonprofits yielded to the professionalization of nonprofits and social enterprises providing these services (Salinas and Rubio, 2001).

In the 1990s, when the contracting out of services consolidated, the sector complexity increased and organizations looked for more sophisticated forms of management. By this time, the Public Administration (central, regional and local) was already the main client of nonprofits, increasing their economic dependence on the public bodies.

There is not a complete census of nonprofit private organizations in Spain, but according to some authors (Ruiz-Olabuénaga, 2001; Cabra de Luna and de Lorenzo, 2005), the size of the third sector in Spain is estimated in 250,000 organizations, of which Fundación Luis Vives (2012) identifies approximately 29,000 providers of social services. Although the Spanish nonprofit sector is large in relation to the Spanish economy, it is slightly below average relative to its counterparts elsewhere in Europe (Ruiz-Olabuénaga et al., 1999).

Spain has a social services-dominant model, where, most of all nonprofit employment is in the social services field (Ruiz-Olabuénaga et al., 1999). In 2010, 38.6 per cent the organizations carried out direct actions in the social services domain, 23.2 per cent of them employ and integrate beneficiaries and 22.1 per cent of them provide health services (Fundación Luis Vives, 2012). Some authors consider third sector entities as essential mechanisms of social wellbeing system (Rodríguez and Monserrat, 1997) or executors of social policies (Ruiz-Olabuénaga, 2000).

Salamon and Sokolowski (2010) studied the civil society sector structure with a model composed of five elements: workforce size, volunteer share, government support, philanthropic support and expressive share. Table II gathers all the information related to Spain.

\begin{tabular}{|c|c|c|}
\hline Dimension of civil society & Size & Description \\
\hline Workforce size & Large & $\begin{array}{l}4.3 \% \text { of economically active population (Salamon } \\
\text { et al., 2003); } 6.1 \% \text { (Cabra de Luna and de Lorenzo, } \\
\text { 2005) }\end{array}$ \\
\hline Volunteer share & Low-medium & $\begin{array}{l}34.8 \% \text { volunteer share of civil society organization } \\
\text { workforce. (average } 38.5 \% \text { for the 35-country } \\
\text { study) }\end{array}$ \\
\hline Government support & Medium-high & $\begin{array}{l}32 \% \text { of civil society organizations income } \\
\text { (according to Salamon } \text { et al., 2003); } 80 \% \text { of social } \\
\text { services providers (according to Salinas and } \\
\text { Rubio, 2001) }\end{array}$ \\
\hline Philanthropic support & Medium-high & $\begin{array}{l}19 \% \text { of the civil society organization revenue } \\
\text { (average } 7 \% \text { in developed countries) }\end{array}$ \\
\hline Expressive share & Smaller than service & $\begin{array}{l}26 \% \text { of civil society organization workforce in } \\
\text { expressive roles (average } 32 \% \text { in developed } \\
\text { countries) }\end{array}$ \\
\hline
\end{tabular}

Sources: Salinas and Rubio (2001); Salamon et al. (2003); Fundación Luis Vives (2012) 
According to the different levels of each one of the five dimensions, they have identified five different types of civil society sectors: liberal, welfare partnership, social democratic, deferred democratization and traditional.

We argue that during the Transition period, Spanish civil society sector was still emerging and it corresponded to the "Deferred Democratization" type (small workforce size, low volunteer share, low government support and limited advocacy). Today, Spanish civil society corresponds to the "Liberal" or "Welfare Partnership" type (large workforce size, low-medium volunteer share, high government support, low philanthropic support and limited expressive share), according to Salamon and Sokolowski's framework.

\subsection{International influences}

Spain has been highly influenced by the European Union, especially before its membership in 1986. Being part of the Union generated a lot of opportunities for Spain in the economic field and a lot of support for economic development came from the European Union in the forms of subsidies and grants.

But another important influence in the conformation of the current model of social enterprise came in the legal and institutional dimension. The social enterprise landscape in Spain is characterized by a big array of legal form that have been influenced by European social economy in the Spanish social enterprise landscape is evident (Salinas and Rubio, 2001; Díaz et al., 2012).

Spain is among the European countries where the concept of social economy is widely accepted by public authorities, the academic and scientific world, as well as in the economy (Monzón and Chaves, 2012). On the contrary, the social enterprise concept arrived after a period where lots of efforts have been done to promote "social economy" from European and Spanish political bodies. Spain, influenced by the European social economy tradition, opted to define the characteristics that identify the social enterprises by allowing all or part of the already existing social economy forms to be considered (Borzaga and Depedri, 2012) instead of defining a new legal form.

\section{Discussion}

The study of Spain shows how the five macro-institutional forces described in Kerlin model (Figure 1) influenced the formation of the Spanish model of social enterprise and helps to understand the conformation process and the typology.

This analysis has generated two main topics for discussion. First, looking to the context at two different moments of time in Spain's recent history, we realize that the model of social enterprise is a dynamic concept that can easily change over time. The evolution of the concept responds mainly to economic, political and social conditions in the country, as it will be discussed in the first part of this section. Second, the Spanish case shows that the diverse regional contexts in the country generate different degrees of development of the social enterprise field. Therefore, it is interesting to explore the specific cultural, economic, political and social conditions at the regional level to fully understand the national model of social enterprise, as it is discussed in the second part of this section.

\subsection{The national model of social enterprise and its evolution over time}

The analysis of the social enterprise in Spain shows that the model has changed in the past 40 years as the economic, political and social landscape also changed. 
During the emergence period of social enterprise, the late 1970s and 1980s, we argue that Spain best aligned with the "Autonomous Mutualism" social enterprise model. In those years, the major macroeconomic forces that influenced the model of social enterprise were:

- The political context institutional structures were weak, but the Government was viewed as responsible for the wellbeing of the country.

- The economic situation can be described as an efficiency-driven economy.

- Post-authoritarian civil society was emerging - given that liberties were restricted during the dictatorship - and early forms of social economy were viewed as a form of social activism. This situation corresponds to a deferred democratic civil society (Salamon and Sokolowski, 2010).

- The international influences were still small, the country was not part of the early stages of the construction of Europe, and it did not become a member of the Union until 1986.

In the past 30 or 40 years, the country experienced a huge and deep transformation, diversifying its economy and building a committed civil society. We can argue that the current model of social enterprise existing in Spain corresponds to the Dependent Focused model:

- In the political context, there are robust and solid institutional structures that promote and support social enterprise at the national, regional and local level. The legislation, even if complex, is favorable (Chaves, 2008) for the development of social economy and social enterprise.

- The economic situation is innovation-driven and Spain is one of the biggest economies in the European Union.

- The civil society fits in the category of welfare partnership (Salamon and Sokolowski, 2010). There is a perception that the well-being of citizens is the Government's responsibility (Salinas and Rubio, 2001). We could infer that civil sector organizations act when there is the necessity of producing social services that Public Administrations are not capable of providing.

- The international influences are important to explain the characteristics of the Spanish social enterprise field today. The European Union has a key role in promoting the concept, and similar legal forms and institutions have been built according to experiences of other neighboring countries.

The Dependent Focused model fits well with the considerable support of Spanish social enterprises by public powers. This support includes several aspects, like the activities they perform and the economic terms, because social enterprises benefit from subsidies and fiscal advantages. We could say that social enterprises work in a coordinated way with public bodies.

Recently, changes in the macroeconomic conditions have been occurring. This effect may be partly caused by the economic crisis and the structural adjustment programs that the Government has been implementing in the last years. The economic situation has caused Spain to reconsider the assumptions about the welfare state and rethink the model of welfare state that we want. The role of public institutions is changing towards 
greater responsibility of the civil society organizations. The role of enterprises is also changing in the complex equilibrium of social well-being. Therefore, in the future, there may be continued changes to the model of social enterprise.

\subsection{Regional differences should be considered to study a national model of social enterprise}

As described earlier, Spain is highly decentralized in the political and administrative arena because the country is formed by 17 regions with individual executive and legislative powers.

In our analysis, we have observed differences in the landscape of social enterprises at a regional level. In particular, two regions present higher prevalence of social enterprises and social economy organizations: Catalonia and the Basque country. Table III shows the number of work integration social enterprises, social employment centers and cooperatives that exist in these two regions compared to the national context.

One can see that the regional dimension should be considered when analyzing the country model of social enterprises. Differences in economic, political and social dimensions among regions can influence the configuration of the social enterprise landscape and can help to explain its emergence.

The decentralization of normative bodies that has taken place in recent years in Spain yielded to different environments for the development of social enterprise. In this sense, the existence of diverse regional frameworks also helps to explain the focus of social enterprises in only one region.

In Spain, we think that some regions - at least Catalonia and the Basque country show enabling environments for social enterprise to arise:

- The Autonomous Communities in Spain show different degrees of economic prosperity. RCI and regional GDP varies across regions, as can be seen in Table I. It is worth noting that the Basque country and Catalonia are the first and fourth highest regions with a GDP per capita and both have a high RCI index (second and fourth over all regions in Spain).

- They have different political and institutional regional bodies and mechanisms to conform the social sector differently: authority to pass specific legislation on

\begin{tabular}{|c|c|c|c|c|c|}
\hline $\begin{array}{l}\text { Type of social } \\
\text { economy organization }\end{array}$ & Catalonia & $\begin{array}{l}\text { Rank among } \\
\text { Spanish regions }\end{array}$ & $\begin{array}{l}\text { Basque } \\
\text { country }\end{array}$ & $\begin{array}{l}\text { Rank among } \\
\text { Spanish regions }\end{array}$ & $\begin{array}{l}\text { Total } \\
\text { Spain }\end{array}$ \\
\hline \multicolumn{6}{|c|}{ Work integration social enterprises (empresas de inserción) } \\
\hline Number & 56 & $1 \mathrm{st}$ & 44 & 2nd & 167 \\
\hline Employees & 983 & 1 st & 671 & 2 nd & 2,435 \\
\hline \multicolumn{6}{|c|}{ Social Employment Centers (centros especiales de empleo) } \\
\hline Number & 56 & 2nd & 27 & 8th & 505 \\
\hline Employees & 5,163 & $3 r d$ & 6,035 & 1 st & 29,831 \\
\hline \multicolumn{6}{|c|}{ Cooperatives (cooperativas) } \\
\hline Number & 4,744 & 1 st & 1,522 & 4 th & 21,257 \\
\hline Employees & 39,034 & $3 r d$ & 52,526 & 1 st & 265,839 \\
\hline
\end{tabular}


social issues, representative bodies and networks, subsidies and others. The development of social enterprises in each Autonomous Community might depend on the regional political initiative: priorities, policies and resources put into action vary from one region to another.

- The sense of belonging to a region or territory is strong in many regions and this could influence the emergence of social enterprise. We suggest that the cultural and social cohesion (Granovetter, 1995) of certain Autonomous Communities in Spain - mainly Catalonia and the Basque country - may have yielded a higher incidence of social enterprises.

It is apparent that the regional and cultural sense of belonging could be the key factor of this outstanding prevalence of socially driven organization in some regions. We suggest that in countries where different cultural groups co-exist (like Spain) the attachment to the region can play an important role in the emergence of social enterprises.

Therefore, the Kerlin model can also be helpful to analyze how regional institutional contexts affect the emergence of social enterprise inside the same country. This could yield to analyze the "ideal regional conditions" to promote social enterprise or a tool to analyze the different development stages of social economy in the 17 Autonomous Communities.

\section{Conclusions}

The term social enterprise has not been defined and delimited in the Spanish context, where it does not correspond to a legal form, but refers to a big category of organizations inside the social economy and the third sector.

The emergence of the social enterprise took place in the late 1970s and the 1980s when the country was experiencing deep transformation from an authoritarian regime to a democracy. In the democratic construction, special power was given to the Autonomous Communities and, therefore, the social economy development was driven by responsiveness to local problems, but also by autonomous framework construction. This led to an uneven and fragmented deployment and diversity of their policies, explained within the regional context (Chaves, 2008).

The main characteristics of a working description of social enterprise in Spain are shown in Table IV.

This article is intended to contribute to the field of social enterprise by broadening the understanding of the growth and development processes of social enterprises into two aspects.

First, it helps to validate from a historical institutionalism perspective, aspects of the Kerlin framework for social enterprise models. Traits of Spain's social enterprise that can be explained by the evolution of its institutional context occurred over the past 40 years. Social enterprise is a dynamic concept and changes according to institutional conditions (social, cultural, political and economic) also bring about changes in the model of social enterprise prevalent in a country. As Kerlin (2013, p. 102) puts it:

[...] it can be expected that these socio-economic institutions will change over time due to shifts in power relations and that social enterprise models for different countries will change over time as well. 


\begin{tabular}{ll}
\hline Outcome emphasis & Social benefit \\
\hline Variation in types of activities & $\begin{array}{l}\text { Low: social integration employment and the provision of social } \\
\text { services. Cross-sector associations represent different types of } \\
\text { entities from different sectors }\end{array}$ \\
Reliance on commercial revenue & $\begin{array}{l}\text { Moderate-Low (income and fees) } \\
\text { High: tax treatment, aid to the direct creation of jobs (subsidies } \\
\text { for salaries, reductions in contributions for social security of } \\
\text { SE policies/subsidies }\end{array}$ \\
& activities \\
No specific. Non-profit co-operatives (cooperativas de iniciativa \\
Social), mutuals, labor worker-owned societies (sociedades \\
laborales), social employment centers (centros especiales de \\
empleo de economia social), mutual benefit societies, work \\
integration social enterprises (empresas de insercion) \\
Moderate-high: democratic principles and citizen participation \\
mechanisms
\end{tabular}

The case of Spain shows how a country has shifted from an Autonomous Mutualism model to a Dependent Focused model in a 40-year period. During the emergence of the social enterprise movement, civil society was still emerging after an authoritarian period and economy was being modernized. In the past four decades, Spanish society's economy has undergone a radical change and today the social enterprise model aligns with the Dependent Focused type.

Second, the Spanish case shows that the analysis of regional differences in the context should be taken into consideration when examining a country's social enterprise space. The analysis explores the importance of the regional context when considering social enterprise models. Specific cultural, political and economic regional conditions can explain the emergence and different stages of development of social-driven organization in some regions. In Spain, we observe two regions that present higher prevalence of social enterprises and social economy organizations: Catalonia and the Basque country. We suggest that these differences can be partly explained by the institutional context of these regions. Social enterprises give response to socioeconomic problems that are embedded in communities; therefore, regional conditions are vital to understanding them. Further research in this field should be done to bridge the gap between theory and practice. An understanding of the differences in social enterprise across the Spanish regions can be helpful to policymakers, funders and practitioners on both national and regional levels.

Today, social enterprise and social economy have an important role in Spain as most social problems have been exacerbated by the economic and financial crisis of recent years (Brandsen et al., 2012). We are facing a time of change and the new circumstances open a wide range of possibilities for the social enterprise, even if considerable challenges exist in the meanwhile (Nogales, 2011).

Some suggestions for future research on the topic include:

- The creation of a common language in order to improve the visibility of social enterprise. This discussion needs to be prioritized among academics in Spain. 
- The empirical mapping and characterization of social enterprises in the country, a task that has not yet been accomplished.

- The understanding of the regional differences in the development of social economy throughout the country, and the analysis of ideal regional conditions that nurture the development of social entrepreneurs and social enterprises at a local level.

A holistic analysis of social enterprise is imperative to better understand the diversity of these organizations. The Kerlin model shows that the interaction of different institutional forces (cultural, economic, social, political and international) can help us to explain typological differences (both at the international and regional level) and the processes of their creation and transformation.

\section{Notes}

1. Social enterprise does not seek to supplant existing concepts of the third sector and the social economy, but to enhance those concepts by shedding light on particular dynamics (Defourny and Nyssens, 2006). Particularly, the social enterprise concept can be seen as a tool for building bridges between institutional fields (Tracey et al., 2011; Doherty et al., 2014) and distinct components of the third sector (Defourny and Nyssens, 2006).

2. The Social Economy Act of 2011 defines the social economy sector by its principles, enumerates the legal forms that can be part of the movement, but does not define the concept of social enterprise itself.

3. Some projects are undertaking this task in Spain at the national (ICSEM, International Comparative Social Enterprise Models, www.iap-socent.be/partners) and regional level (Innobasque, www.innobasque.com/home.aspx?tabid=806).

4. Not all of these organizations can be described as social enterprises because it is not clear today if the guiding values respond to the core principles of social enterprises: a) some of them do not carry out market activities, but are entities aimed to represent a community, and b) some of them do not clearly qualify as having social goals (like some cooperatives).

5. Like communal cropping, fishing and shepherding groups in Castillian regions during the Reconquista period and the Court of the Waters in Valencia (Tribunal de las Aguas) in the thirteenth century.

6. The National Institute for the Promotion of Social Economy (Instituto Nacional de Fomento de la Economia Social) in 1990 which had a key role in improving the visibility of social economy (Fajardo, 2009); the Socioeconomic Council of Spain (Consejo Económico y Social de España) in 1991 that will represent a permanent platform for debate and dialogue with the members of the sector (Valdés Dal-Re, 2009); and the Spanish Federation of Social Economy Entities (Confederación Empresarial Española de Economia Social, CEPES), in 1992, a nationwide cross-sector organization to represent all the different members of the social economy (Valdés Dal-Re, 2009).

7. These languages are spoken by the following native speakers: 7,220,420 (Catalan); 3,185,000 (Galician) and 657,872 (Basque). There are other languages and dialects that are spoken - like Valencian, Aranese (a dialect of Occitan), Asturian, Aragonese, Leonese and Extremaduran but the communities are smaller than those of the major languages (Ethnologue, 2013). 